\title{
$\mathbf{J}|\mathbf{A}| \mathbf{C} \mid \mathbf{S}$ \\ $\overline{\text { COMMUNICATIONS }}$
}

Published on Web 03/15/2002

\section{Tetracyanide-Bridged Divanadium Complexes: Redox Switching between Strong Antiferromagnetic and Strong Ferromagnetic Coupling}

\author{
Matthew P. Shores and Jeffrey R. Long* \\ Department of Chemistry, University of California, Berkeley, California 94720-1460
}

Received January 2, 2002

The recent observations of slow magnetic relaxation ${ }^{1}$ and quantum tunneling of the magnetization ${ }^{2}$ in certain transition metal clusters have bolstered interest in the synthesis of new high-spin molecules. Of particular interest to us are metal-cyanide cluster systems, which offer the possibility of adjusting critical groundstate magnetic properties through the substitution of different transition metal ions into a known cluster geometry. ${ }^{3}$ With the expectation of enhancing the magnetic anisotropy in high-spin species incorporating $\left[\left(\mathrm{Me}_{3} \operatorname{tacn}\right) \mathrm{Cr}(\mathrm{CN})_{3}\right]\left(\mathrm{Me}_{3} \mathrm{tacn}=N, N^{\prime}, N^{\prime \prime}\right.$ trimethyl-1,4,7-triazacyclononane), ${ }^{3 \mathrm{ab}}$ we have pursued the synthesis of $\left[\left(\mathrm{Me}_{3} \mathrm{tacn}\right) \mathrm{V}(\mathrm{CN})_{3}\right]$. In so doing, a reaction was discovered wherein the oligomerization of cyanide leads to formation of a tetracyanide-bridged dinuclear complex, $\left[\left(\mathrm{Me}_{3} \mathrm{tacn}\right)_{2} \mathrm{~V}_{2}(\mathrm{CN})_{4}(\mu\right.$ $\left.\mathrm{C}_{4} \mathrm{~N}_{4}\right)$ ]. Here, we report the preparation and magnetic properties of this unusual molecule, which exhibits strong antiferromagnetic coupling that switches to strong ferromagnetic coupling upon reduction by one electron. ${ }^{4}$

Our approach to synthesizing the intended tricyanide complex followed a method previously employed in generating analogous complexes: ${ }^{3 a c}$ the substitution of cyanide for triflate. Under a dinitrogen atmosphere, $\mathrm{LiCN} \cdot \mathrm{DMF}^{5}(0.49 \mathrm{~g}, 4.6 \mathrm{mmol})$ was added to a solution of $\left[\left(\mathrm{Me}_{3} \mathrm{tacn}\right) \mathrm{V}\left(\mathrm{CF}_{3} \mathrm{SO}_{3}\right)_{3}\right]^{6}(1.0 \mathrm{~g}, 1.5 \mathrm{mmol})$ in 3 $\mathrm{mL}$ of DMF. The solution was stirred at room temperature, gradually changing color from dark blue to yellow-brown to redbrown over the course of $3 \mathrm{~h}$. After 3 days of stirring, a dark red precipitate was collected by filtration and washed with successive aliquots of DMF $(0.5 \mathrm{~mL})$, THF (3 mL), and ether ( $3 \mathrm{~mL})$. In air, a solution of the solid in $100 \mathrm{~mL}$ of hot water was filtered, and the filtrate was concentrated to a volume of $5 \mathrm{~mL}$. The ensuing dichroic red-green crystals were collected by filtration, washed with $5 \mathrm{~mL}$ of THF, and dried in air to afford $0.15 \mathrm{~g}(19 \%)$ of $\left[\left(\mathrm{Me}_{3} \operatorname{tacn}\right)_{2} \mathrm{~V}_{2^{-}}\right.$ $\left.(\mathrm{CN})_{4}\left(\mu-\mathrm{C}_{4} \mathrm{~N}_{4}\right)\right] \cdot 2 \mathrm{H}_{2} \mathrm{O}\left(\mathbf{1} \cdot 2 \mathrm{H}_{2} \mathrm{O}\right){ }^{7}$

Red-green block-shaped crystals of $\mathbf{1} \cdot 2$.5DMF suitable for X-ray analysis ${ }^{8}$ were obtained by allowing the reaction mixture to stand for 4 days without stirring. Figure 1 (upper) depicts the structure of the unexpected dinuclear complex, $\left[\left(\mathrm{Me}_{3} \mathrm{tacn}\right)_{2} \mathrm{~V}_{2}(\mathrm{CN})_{4}\left(\mu-\mathrm{C}_{4} \mathrm{~N}_{4}\right)\right]$, in which two pseudooctahedral $\mathrm{V}^{\mathrm{IV}}$ centers are linked through a tetracyanide bridge. Presumably arising from the oligomerization of four cyanide units, the $\mathrm{C}_{4} \mathrm{~N}_{4}{ }^{4-}$ bridging moiety can be viewed as the quadruply deprotonated form of diaminofumaronitrile. The short $\mathrm{V}(1)-\mathrm{N}(1)$ distance of $1.721(5) \AA$ is consistent with an imido type linkage, suggesting, together with the interatomic distances and angles observed within the tetracyanide bridge (see legend of Figure 1), significant contributions from the resonance structures depicted in Scheme 1.

The oligomerization of $\mathrm{HCN}$ has been widely studied, owing to its putative role in the prebiotic synthesis of purines, pyrimidines, and amino acids. ${ }^{9}$ The involvement of transition metals in promoting

* Address correspondence to this author. E-mail: jlong@cchem.berkeley.edu.
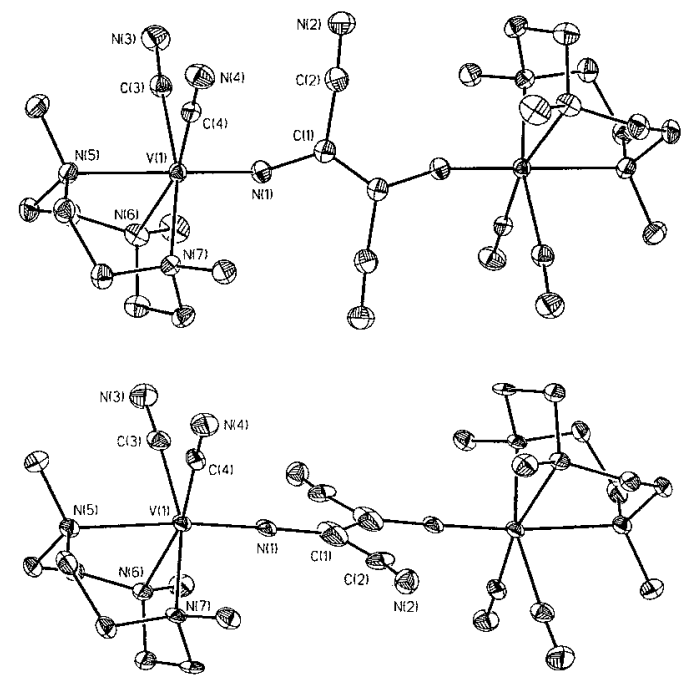

Figure 1. Structures of $\left[\left(\mathrm{Me}_{3} \mathrm{tacn}\right)_{2} \mathrm{~V}_{2}(\mathrm{CN})_{4}\left(\mu-\mathrm{C}_{4} \mathrm{~N}_{4}\right)\right]$ (upper) and $\left[\left(\mathrm{Me}_{3}-\right.\right.$ tacn $\left.)_{2} \mathrm{~V}_{2}(\mathrm{CN})_{4}\left(\mu-\mathrm{C}_{4} \mathrm{~N}_{4}\right)\right]^{1-}$ (lower), as observed in $\mathbf{1} \cdot 2.5 \mathrm{DMF}$ and $\mathbf{2} \cdot 4 \mathrm{MeCN}$; $\mathrm{H}$ atoms are omitted for clarity. Both molecules reside on a crystallographic inversion center. Selected interatomic distances $(\AA)$ and angles (deg) from 1·2.5DMF and 2•4MeCN, respectively: $\mathrm{V}(1)-\mathrm{N}(1) 1.721(5), 1.740(4)$; $\mathrm{V}(1)-\mathrm{C}(3) 2.129(7), 2.132(6) ; \mathrm{V}(1)-\mathrm{C}(4) 2.122(8), 2.141(6) ; \mathrm{V}(1)-\mathrm{N}(5)$ 2.252(5), 2.285(4); V(1)-N(6) 2.178(5), 2.213(4); V(1)-N(7) 2.168(5), $2.197(4) ; \mathrm{N}(1)-\mathrm{C}(1) 1.359(8), 1.356(7) ; \mathrm{C}(1)-\mathrm{C}(2) 1.48(1), 1.55(1) ; \mathrm{C}(1)-$ $\mathrm{C}\left(1^{\prime}\right) 1.34(1), 1.31(1) ; \mathrm{C}(2)-\mathrm{N}(2) 1.142(9), 1.129(6) ; \mathrm{C}(3)-\mathrm{N}(3) 1.125-$

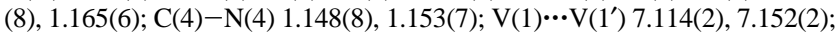
$\mathrm{N}(1)-\mathrm{V}(1)-\mathrm{C}(4) 92.6(2), 95.4(2) ; \mathrm{N}(1)-\mathrm{V}(1)-\mathrm{N}(7) 100.0(2), 97.1(2)$; $\mathrm{N}(1)-\mathrm{V}(1)-\mathrm{N}(5)$ 177.8(2), 174.5(2); C(3)-V(1)-C(4) 88.9(3), 90.4(2); $\mathrm{V}(1)-\mathrm{C}(4)-\mathrm{N}(4)$ 177.2(6), 178.5(5); V(1)-N(1)-C(1) 161.9(5), 175.2 (5); $\mathrm{N}(1)-\mathrm{C}(1)-\mathrm{C}\left(1^{\prime}\right)$ 126.4(8), 131(1); N(1)-C(1)-C(2) 117.1(5), 119.7(6); $\mathrm{C}(1)-\mathrm{C}(2)-\mathrm{N}(2) 175.8(8), 169.6(6)$.

Scheme 1. Some Resonance Forms of the Tetracyanide Bridge in 1

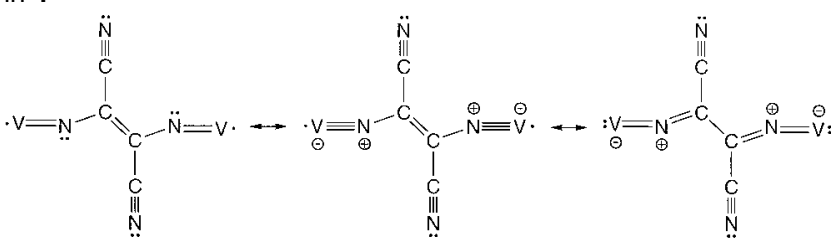

such processes, however, is less well-known. Most pertinently, the reductive coupling of acetonitrile in the presence of $\mathrm{MCl}_{4}(\mathrm{M}=$ $\mathrm{Nb}, \mathrm{Ta}$ ) leads to dinuclear $\mathrm{M}^{\mathrm{V}}-\mathrm{M}^{\mathrm{V}}$ products with a bridging ligand related to that in $\mathbf{1}$ through replacement of the terminal nitriles with methyl groups. ${ }^{10}$ In addition, photolysis of $\left[\mathrm{Mn}(\mathrm{CN})_{6}\right]^{2-}$ has been found to generate small amounts of the oxidized oligocyanides $\mathrm{C}_{4} \mathrm{~N}_{4}{ }^{-}$and $\mathrm{C}_{12} \mathrm{~N}_{12}{ }^{2-}$, ${ }^{11}$ although, to our knowledge, no such reactions have yet led directly to bridged multinuclear species.

The conjugated pathway provided by the bridging tetracyanide ligand leads to strong antiferrromagnetic exchange coupling between 


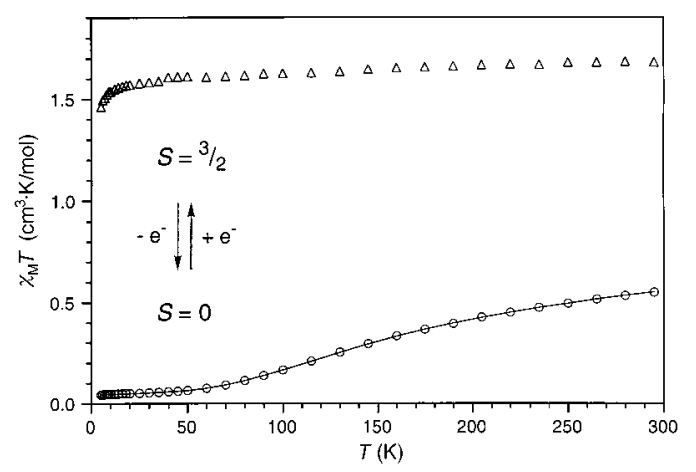

Figure 2. Magnetic behavior of compounds $1 \cdot 2 \mathrm{H}_{2} \mathrm{O}$ (circles) and $\mathbf{2}$ (triangles) in applied fields of 20 and $10 \mathrm{kG}$, respectively. The solid line represents a fit to the data for $1 \cdot 2 \mathrm{H}_{2} \mathrm{O}$, calculated with $J=-112 \mathrm{~cm}^{-1}$, $g=1.83, \mathrm{TIP}=350 \times 10^{-6} \mathrm{cgsu} / \mathrm{mol}$, and $P=0.038$.

the two $\mathrm{V}^{\mathrm{IV}}$ centers in $\mathbf{1} \cdot 2 \mathrm{H}_{2} \mathrm{O}$ (see Figure 2). At $295 \mathrm{~K}, \chi_{\mathrm{M}} T$ is $0.550 \mathrm{~cm}^{3} \mathrm{~K} / \mathrm{mol}$, well below the value of $1.00 \mathrm{~cm}^{3} \mathrm{~K} / \mathrm{mol}$ predicted for two uncoupled $S=1 / 2$ ions with $g=2.00$. As the temperature is lowered, $\chi_{\mathrm{M}} T$ decreases steadily, approaching the value of zero expected for an $S=0$ ground state. The residual moment of 0.044 $\mathrm{cm}^{3} \mathrm{~K} / \mathrm{mol}$ at $5 \mathrm{~K}$ is attributed to the presence of a small amount of an unidentified paramagnetic impurity. The best fit to the data, obtained with use of MAGFIT $3.1^{12}$ and an exchange Hamiltonian of the form $\hat{H}=-2 J \hat{S}_{\mathrm{V}(1)} \cdot \hat{S}_{\mathrm{V}(2)}$, gives $J=-112 \mathrm{~cm}^{-1}$ and $g=$ 1.83 .

The cyclic voltammogram of $\mathbf{1}$ in $\mathrm{MeCN}$ displays a reversible wave corresponding to the $\left[\left(\mathrm{Me}_{3} \operatorname{tacn}\right)_{2} \mathrm{~V}_{2}(\mathrm{CN})_{4}\left(\mu-\mathrm{C}_{4} \mathrm{~N}_{4}\right)\right]^{0 / 1-}$ couple at $E_{1 / 2}=-1.098 \mathrm{~V}\left(\Delta E_{\mathrm{p}}=74 \mathrm{mV}\right)$ versus $\left[\mathrm{FeCp}_{2}\right]^{0 / 1+}$. A second reduction occurs irreversibly at $-2.327 \mathrm{~V}$. The large separation between these two reduction events suggests that delocalization of the extra electron between the two vanadium centers leads to Class III mixed-valence behavior in $\left[\left(\mathrm{Me}_{3} \operatorname{tacn}\right)_{2} \mathrm{~V}_{2}(\mathrm{CN})_{4}\left(\mu-\mathrm{C}_{4} \mathrm{~N}_{4}\right)\right]^{1-}$ with the remarkably high comproportionation constant of $K_{\mathrm{c}} \approx 10^{20}{ }^{13}$

The reduced monoanion was prepared in bulk via chemical reduction. Under a dinitrogen atmosphere, solid $\mathrm{CoCp}_{2}(0.11 \mathrm{~g}$, $0.58 \mathrm{mmol})$ was added to a solution of $1(0.10 \mathrm{~g}, 0.15 \mathrm{mmol})$ in 10 $\mathrm{mL}$ of $\mathrm{MeCN}$. The resulting violet solution was stirred for $30 \mathrm{~min}$, after which a small amount of dark solid was separated by filtration and washed with $20 \mathrm{~mL}$ of MeCN. Addition of $150 \mathrm{~mL}$ of ether to the filtrate produced a violet precipitate, which was collected by filtration, washed with ether, and dried under dinitrogen to yield $0.11 \mathrm{~g}(87 \%)$ of $\left(\mathrm{CoCp}_{2}\right)\left[\left(\mathrm{Me}_{3} \mathrm{tacn}\right)_{2} \mathrm{~V}_{2}(\mathrm{CN})_{4}\left(\mu-\mathrm{C}_{4} \mathrm{~N}_{4}\right)\right](2) .{ }^{14}$ The IR spectrum of 2 reveals no splitting in the lowest energy $v_{\mathrm{CN}}$ band, which we attribute to stretching of the metal-bound cyanide ligands. This observation lends further support to a delocalized description of the electronic structure, in which each metal center is best viewed as $\mathrm{V}^{3.5+}$ on the vibrational time scale.

Diffusion of ether into a concentrated solution of $\mathbf{2}$ in $\mathrm{MeCN}$ afforded dark red block-shaped crystals suitable for X-ray analysis. ${ }^{8}$ A striking difference between the structures of the reduced and neutral complexes (see Figure 1) lies in the rotation of the planar tetracyanide bridge by $\sim 90^{\circ}$. More subtle differences are apparent in the interatomic distances and angles, as compared in the legend of Figure 1; most notably, the $\mathrm{V}(1)-\mathrm{N}(1)-\mathrm{C}(1)$ angle becomes more linear upon reduction.

Delocalization of the additional electron in the reduced complex leads to dramatically different magnetic properties for compound 2 (see Figure 2). Here, the value of $\chi_{M} T$ varies little with temperature, and is $1.682 \mathrm{~cm}^{3} \mathrm{~K} / \mathrm{mol}$ at $295 \mathrm{~K}$. This behavior indicates a well-isolated $S=3 / 2$ ground state, with essentially no population of spin-excited states at room temperature. The slight attenuation of $\chi_{\mathrm{M}} T$ with decreasing temperature is consistent with the effects of temperature-independent paramagnetism and, at lower temperatures, zero-field splitting. Thus, resonance exchange of the extra electron between symmetry-equivalent vanadium centers appears to overwhelm the antiferromagnetic Heisenberg exchange interaction $(|B| \gg|J|),{ }^{15}$ leading to strong ferromagnetic coupling in $\left[\left(\mathrm{Me}_{3} \operatorname{tacn}\right)_{2} \mathrm{~V}_{2}(\mathrm{CN})_{4}\left(\mu-\mathrm{C}_{4} \mathrm{~N}_{4}\right)\right]^{1-} \cdot{ }^{16,17}$

The foregoing results evoke a mechanism for generating highspin mixed-valence species with ground-state properties that persist up to room temperature. Efforts to synthesize higher-nuclearity clusters incorporating tetracyanide and related bridging ligands are ongoing.

Acknowledgment. This research was funded by NSF Grant No. CHE-0072691. We thank Unilever for a donation of $\mathrm{Me}_{3}$ tacn, Prof. J. K. McCusker, J. J. Sokol, and N. R. M. Crawford for helpful discussions, and Prof. D. N. Hendrickson for supplying software used to fit the magnetic susceptibility.

Supporting Information Available: Tables of crystallographic information for the structures of $\mathbf{1} \cdot 2.5 \mathrm{DMF}$ and $\mathbf{2} \cdot 4 \mathrm{MeCN}$ (PDF) and an X-ray crystallographic file (CIF). This material is available free of charge via the Internet at http://pubs.acs.org.

\section{References}

(1) (a) Sessoli, R.; Tsai, H.-L.; Schake, A. R.; Wang, J. B.; Folting, K.; Gatteschi, D.; Christou, G.; Hendrickson, D. N. J. Am. Chem. Soc. 1993 115, 1804. (b) Sessoli, R.; Gatteschi, D.; Caneschi, A.; Novak, M. A. Nature 1993, 365, 141 .

(2) (a) Friedman, J. R.; Sarachik, M. P.; Tejada, J.; Ziolo, R. Phys. Rev. Lett. 1996, 76, 3830. (b) Thomas, L.; Lionti, F.; Ballou, R.; Gatteschi, D.; Sessoli, R.; Barbara, B. Nature 1996, 383, 145.

(3) (a) Berseth, P. A.; Sokol, J. J.; Shores, M. P.; Heinrich, J. L.; Long, J. R. J. Am. Chem. Soc. 2000, 122, 9655. (b) Heinrich, J. L.; Sokol, J. J.; Hee, A. G.; Long, J. R. J. Solid State Chem. 2001, 159, 293. (c) Shores, M. P.; Sokol, J. J.; Long, J. R. J. Am. Chem. Soc. 2002, 124, 2279.

(4) A similar switching behavior was recently demonstrated for a weakly coupled organic radical system: Shultz, D. A.; Kumar, R. K. J. Am. Chem. Soc. 2001, 123, 6431 .

(5) Markley, T. J.; Toby, B. H.; Pearlstein, R. M.; Ramprasad, D. Inorg. Chem. 1997, 36, 3376 .

(6) Knopp, P.; Wieghardt, K.; Nuber, B.; Weiss, J.; Sheldrick, W. S. Inorg. Chem. 1990, 29, 363.

(7) Characterization of $\mathbf{1} \cdot 2 \mathrm{H}_{2} \mathrm{O}$ : Absorption spectrum $\left(\mathrm{H}_{2} \mathrm{O}\right) \lambda_{\max }\left(\epsilon_{\mathrm{M}}\right) 264$ (15300), 281 (21000), 360 (8250), 496 (16550), 663 (374), 700 (sh, 291), $804(175), 900(\mathrm{sh}, 126) \mathrm{nm}$. IR $v_{\mathrm{CN}} 2225$ (sh), 2214, $2114 \mathrm{~cm}^{-1} \cdot \mu_{\mathrm{eff}}=$ $2.10 \mu_{\mathrm{B}}$ at $295 \mathrm{~K}$. FT-ICR ES ${ }^{-}-\mathrm{MS}\left(\mathrm{H}_{2} \mathrm{O} / \mathrm{MeOH}\right) \mathrm{m} / \mathrm{z} 626.26\left([\mathbf{1}-\mathrm{CN}]^{+}\right)$ Anal. Calcd for $\mathrm{C}_{26} \mathrm{H}_{46} \mathrm{~N}_{14} \mathrm{O}_{2} \mathrm{~V}_{2}$ : C, 45.35; H, 6.73; N, 28.48. Found: C, $45.72 ; \mathrm{H}, 7.01 ; \mathrm{N}, 28.30$.

(8) Crystal and structure refinement parameters: 1-2.5DMF: $\mathrm{C}_{33.5} \mathrm{H}_{59.5} \mathrm{~N}_{16.5-}$ $\mathrm{O}_{2.5} \mathrm{~V}_{2}, T=163 \mathrm{~K}, P b c n, Z=4, a=18.905(4) \AA, b=14.931(3) \AA$ $c=15.295(3) \AA, V=4317(2) \AA^{3}, d_{\text {calc }}=1.285 \mathrm{~g} / \mathrm{cm}^{3}, R_{1}=0.0772$, $w R_{2}=0.2184 .2 \cdot 4 \mathrm{MeCN}: \mathrm{C}_{44} \mathrm{H}_{64} \mathrm{CoN}_{18} \mathrm{~V}_{2}, T=165 \mathrm{~K}, P 1, Z=2, a=$ 12.578(1) $\AA, b=14.391(1) \AA, c=14.546(1) \AA, \alpha=102.69(1)^{\circ}, \beta=$ $91.498(1)^{\circ}, \gamma=98.530(1)^{\circ}, V=2535.5(3) \AA^{3}, d_{\text {calc }}=1.318 \mathrm{~g} / \mathrm{cm}^{3}, R_{1}=$ $0.0605, w R_{2}=0.1318$. Data were collected on a Siemens SMART diffractometer using graphite monochromated $\operatorname{Mo~} \operatorname{Ko}(\lambda=0.71073 \AA)$ radiation, and were corrected for Lorentz, polarization, and absorption effects. The structures were solved by direct methods with the aid of successive difference Fourier maps, and were refined against all data using SHELXTL 5.0.

(9) Lead references: (a) Ferris, J. P.; Edelson, E. H. J. Org. Chem. 1978, 43, 3989. (b) Schwartz, A. W.; Bakker, C. G. Science 1989, 245, 1102.

(10) (a) Finn, P. A.; King, M. S.; Kilty, P. A.; McCarley, R. E. J. Am. Chem. Soc. 1975, 97, 220. (b) Cotton, F. A.; Hall, W. T. Inorg. Chem. 1978, 17, 3525 .

(11) Manson, J. L.; Buschmann, W. E.; Miller, J. S. Inorg. Chem. 2001, 40, 1926.

(12) Schmitt, E. A. Ph.D. Thesis, University of Illinois, 1995

(13) Creutz, C. Prog. Inorg. Chem. 1983, 30, 1.

(14) Characterization of 2: Absorption spectrum $(\mathrm{MeCN}) \lambda_{\max }\left(\epsilon_{\mathrm{M}}\right) 262$ (33200), 360 (sh, 5700), 515 (10400) nm (no other absorption bands were observed in the region $200-2200 \mathrm{~nm})$. IR $v_{\mathrm{CN}} 2242(\mathrm{w}), 2156,2096 \mathrm{~cm}^{-1}$. $\mu_{\text {eff }}=3.67 \mu_{\mathrm{B}}$ at $295 \mathrm{~K}$. Anal. Calcd for $\mathrm{C}_{36} \mathrm{H}_{52} \mathrm{CoN}_{14} \mathrm{~V}_{2}: \mathrm{C}, 51.37 ; \mathrm{H}$, 6.23 ; N, 23.30. Found: C, 51.30; H, 6.24; N, 23.33.

(15) Blondin, G.; Girerd, J.-J. Chem. Rev. 1990, 90, 1359.

(16) Bencini, A.; Gatteschi, D.; Sacconi, L. Inorg. Chem. 1978, 17, 2670.

(17) An alternative explanation for the magnetic properties of 2 that cannot yet be discounted involves strong ferromagnetic coupling between two $\mathrm{V}^{\mathrm{IV}}$ centers and a radical $\mathrm{C}_{4} \mathrm{~N}_{4}{ }^{5-}$ bridging unit.

JA025512N 